Article

\title{
Examining Household Food Waste Behaviors and the Determinants in Korea Using New Questions in a National Household Survey
}

\author{
Sanghyo Kim ${ }^{1}$ and Sang Hyeon Lee ${ }^{2, *(1)}$ \\ 1 Division of Agri-Food System Research, Korea Rural Economic Institute, Naju 58217, Korea; skim@krei.re.kr \\ 2 Department of Agricultural \& Resource Economics, Kangwon National University, Chuncheon 24341, Korea \\ * Correspondence: shl@kangwon.ac.kr; Tel.: +82-33-250-8662
}

Received: 18 September 2020; Accepted: 12 October 2020; Published: 14 October 2020

\begin{abstract}
Despite active international efforts to reduce food waste, there are only a few academic researches and policy movements in Korea. One of the many causes of this is the lack of relevant statistics on household food waste behaviors. This study is the first comprehensive study on the food waste behaviors of Korean households and determinants, providing, based on the analysis of the first representative national-level household survey, useful insights and policy implications for countries with a similar environment and situation to Korea. This study found that approximately $63 \%$ of households discharge food waste of less than $500 \mathrm{~g}$ a day, and the amount varies by region significantly, implying a potential possibility of food waste reduction by regionally differentiated strategies. It is also found that the amount of food waste is on the rise in Korea, and the most widely used volume-rate disposal system in Korea is public food waste collection boxes (29.44\%). Regression analyses indicate that policy efforts should focus on raising awareness of the importance of reducing food waste; for example, by promoting campaigns to encourage desirable food purchases, implementing dietary education, and discovering an optimal volume-rate disposal system that is regionally specific. This study suggest that the Korean government should actively participate in international efforts, establish an integrated system in which stakeholders and policy makers can cooperate, develop indicators and set targets for food waste reduction, and encourage diverse implementation to develop policies tailored to domestic and regional environments.
\end{abstract}

Keywords: food waste; household behavior; consumer awareness; intensity of efforts to reduce food waste; volume-rate disposal system

\section{Introduction}

Approximately $33 \%$ of the final food demand worldwide is thrown away as food loss and waste. The value of food loss and waste is estimated to be over $\$ 900$ billion [1]. This value is at the level where one-eighth of the world population can be saved from nutritional deficiencies. From this global perspective, the food loss and waste issue is closely associated with the global food security problem that might be incurred by inefficient allocation of food resources across countries. Additionally, from the standpoint of an environmental view, the generation of food waste increases the environmental burden as it causes not only the additional emission of greenhouse gases, but also an efficiency decrease in water and land use [1]. Therefore, the food loss and waste issue has been an emerging international issue.

Even at the individual national level, the food waste and loss issue is a critical issue because it can be regarded as an economic loss caused by wasted investments such as depreciation of capital. In addition, as food waste and loss is known to have a negative impact on national food security, 
farm income, and consumer welfare [2] it is a topic that attracts the attention of policymakers in every country.

As sustainable development emerges as an important topic, reducing food loss and waste is attracting attention from everyone around the world in a perspective of efficient resource utilization and environmental cost reduction. The 17 goals of the United Nations (UN)' 2030 agenda for sustainable development include reducing food loss and waste, particularly with goals 2 and 12 calling for targeting zero hunger and reducing food loss and waste by 2030 [3]. The Food and Agriculture Organization of UN (FAO) suggested eight causes of food loss and waste: (1) overproduction of food/technical limitations of food handling and storage; (2) urbanization, dietary change, increase in single-person households; (3) mass production and mass distribution of food; (4) food consumption culture: excessive food preparation in Asia; (5) excessive food purchase due to sales promotion; (6) distrust of food labeling and anxiety about food safety; (7) low acceptance level of visually incomplete agricultural products; and (8) lack of consumer education in food disposal [4].

Food loss and waste can occur throughout the upstream and downstream phases of the food supply chain. In general, food loss is the decrease in quantity or quality of foods in the stages of production, processing, packaging, storage, and distribution along the food supply chain, while food waste is the qualitative or qualitative deterioration of foods by retailers, food service providers, and households. According to the FAO, food loss and waste in developing countries occur mainly in the post-harvest management and processing stages, while in developed countries they occur largely in the consumption stage [4]. Therefore, an optimal strategy specific to each country would be necessary to efficiently reduce food loss and waste. As can be inferred from the fact that six of the eight causes of food loss and waste suggested by the FAO ( $\# 2, \# 4, \# 5, \# 6, \# 7$, and \#8), particularly the eighth cause, are associated with the consumption stage, which is the most downstream stage of the food supply chain, food waste is a relatively more important problem these days. For this reason, this study focuses on the 'food waste' behaviors of Korean households with the aim of reducing it.

Despite active international efforts and researches implemented to reduce food loss and waste, there are only a few academic researches and policy movements/changes in the arena of food loss and waste in Korea with a focus on the introduction of a volume-rate disposal system and the establishment of a declarative comprehensive plan [5-7]. In order for Korea to keep pace with international efforts in reducing food loss and waste, it is essential to understand the actual status and determining factors related to food loss and waste. In particular, because there have been few studies on the actual status on the food waste of households in Korea, even very basic data that policy makers can use in the development of policies to reduce food loss and waste in the consumption stage are currently scarce.

This study is conducted to derive policy implications by understanding households' food waste behaviors using the Consumer Behavior Survey for Foods (CBSF), implemented by the Korea Rural Economic Institute [8]. The CBSF is the first national-level survey to investigate the food waste behaviors by representative Korean households and thus provides a better understanding of the current status of food waste in Korea. In order to derive practically applicable policy implications based on the analysis results, recent policies and research conducted by each country, as well as by international organizations for the purpose of reducing food waste and loss, are widely reviewed. This study is the first comprehensive study on the food waste behaviors of Korean households and its determinants. Korea can be considered as the country that is in a transition from a developing country to a more developed country (e.g., countries in Organization for Economic Cooperation and Development (OECD)); hence, this study is expected to contribute to the related research literature as well as to policy design by countries with a similar environment and situation to Korea by providing, based on the analysis of the first representative national-level household survey, useful insights and policies. 


\section{Review of Literature}

\subsection{Related Studies}

Studies on food waste and loss have been conducted in many countries in various aspects. generally, they can be classified based on the main subjects responsible for solving the food waste and loss issue; the first subject would be consumer, and the second one the structure and system of society.

Consumer-related research can again be classified into (1) consumer perceptions and attitudes related to food waste and loss, (2) analysis of household behavior on food waste, (3) causes of and potential solutions for food waste, and (4) information effect on consumer behavior in reducing food waste.

Qi and Roe [9] constructed a model of American consumers' perceptions and attitudes toward food waste using data from a national survey of US residents. As a result of the analysis, they found that consumers' awareness of food waste in the United States generally lags considerably when judged on the basis of awareness of food waste and public interest in environmental threats caused by food waste. For example, a high portion (approximately 60\%) of all respondents agreed that some food waste was necessary to keep the taste fresh. In addition, the survey indicated that US consumers have a considerably low level of concern about environmental damages caused by food waste. They also found that food labeling "guides or initiatives", removing the sell-by dates, for example, could reduce consumer confusion about food labeling, and they proposed that food waste can be efficiently reduced by alleviating the conflicting relationship between food waste and food-related disease outbreaks. This study analyzed that food labeling initiatives may be particularly effective for high-income households and women who feel guilty about wasting foods while wasting foods due to health concerns at the same time [5].

Radzymińska et al. [10] analyzed the attitudes and behaviors of young Polish consumers about food waste based on data published in pilot research and previous studies to present policy implications. According to their results, despite the fact that Polish consumers have knowledge of how to reduce food waste, most of them have made no effort to reduce food waste [6]. This means that knowledge and practice may not be consistent in the field of reducing food waste; thus, there is a need for a policy device that can induce practice beyond the level of providing knowledge. They suggested that a campaign on food waste and loss could be an effective solution in driving changes in consumer attitudes and behaviors. Additionally, they argued that appropriately selected information should be provided through the mass media that supports the solution to the food waste problem when leading the campaign. Similar to Radzymińska et al. [10], Refsgaard and Magnussen [11] studied the behaviors and attitudes of people regarding the recycling of food waste in two Norwegian municipalities with different technology levels and organizational systems. This study confirmed that attitudes and behaviors toward food waste are influenced by practicalities such as knowledge on food waste reduction and recycling, knowledge of consequences of food waste, and time/space/convenience. In addition, differences in institutional environments had different effects on attitudes toward food waste and loss, while it was found that food waste and loss were relatively more sensitive at the group level than at the individual level.

Secondi et al. [12] conducted a study on the analysis model of food waste behavior of households. This study investigated key regulations and actions at various levels of administration and applied a two-step framework to model the complex food waste-related behavior of households. In addition, based on the 2013 Flash Eurobarometer survey, the behavior of citizens in the European Union (EU)-27 on food waste was examined. From an individual level, people living in cities and large cities tend to generate more food waste; hence, the need to diversify policy interventions at the level of local governments by the degree of urbanization was emphasized. In addition, it was found that the level of education, practices, attitudes, and interests in food waste are statistically and significantly related to the individual's behavior toward food waste [12]. 
Halloran et al. [13] investigated the case of Denmark to figure out the causes of food waste, and the prevention of food waste worth $€ 1.18$ billion a year and how to increase food recycling were examined. The study emphasized the need for improved communication, more efficient food packaging, and accurate interpretation of food labeling by consumers as a way to reduce food waste and loss. Meanwhile, they also suggested that support for integrated agricultural and food systems that optimize food use and reduce the waste of resources should be strengthened. Finally, Halloran et al. [13] also insisted that cooperation with various stakeholders, especially public-private partnerships at the international level, should be included as a sustainable solution to reduce food waste and loss in Denmark.

Fanelli [14] highlighting the importance of individual level analysis, identified the major causes of food waste by Italian consumers, and drew a causal map using data from an online survey. They concluded that (subjective) consumer behavior as well as (objective) household food shopping and socioeconomic status are more influential causes of food waste. They also emphasized the importance of information provision and education policies to change consumer awareness and lifestyles. Falasconi et al. [15] also found that consumer perceptions of the cause of food waste and food purchase pattern played an important role in determining the amount of household food waste in Italy, agreeing the suggestions by Fanelli [14].

Qi and Roe [16] analyzed, in situational experiments and surveys, whether consumers' perceptions that environmental damage caused by food waste is mitigated by recycling technology (composting technology) inhibited individuals' behaviors to reduce food waste. It was found that providing participants with information on the negative environmental and economic effects of food waste could significantly reduce the total amount of solid food waste compared to the control situation without food waste reduction or food waste recycling policies. On the other hand, it was found that the generation of solid food waste was significantly higher when the participants were informed that food waste would be composted than when only information on food waste reduction policies was provided. This means the promotion/advertisement of technologies and policies (recycling technologies, composting technologies) that mitigate the environmental damage of food waste can halve the effect of policies, encouraging individual consumers to reduce food waste (e.g., information rebound effect).

Meanwhile, a number of studies have also been conducted on social structures and systems related to the reduction of food waste and loss. Miller and Welch [17] identified and evaluated the deficiencies in the food system that led to a failure in nutritional preservation of micronutrients and sought and evaluated strategies to address them. They emphasized the need for improvement in the food system, arguing that improving the post-harvest processing system for fresh fruits and vegetables, one of the most wasted and lost items, would have the potential to prevent the failure of the nutritional preservation of micronutrients. The proposed measures include (1) Research and Development (R\&D) investment in food processing and food storage technology; (2) finding strategies to solve the problem from the overall perspective of the food system; (3) raising capacity related to agriculture, food processing, and nutrition education; and (4) developing technologies to improve the biological preservation of foods.

Lee et al. [18] presented a stochastic model of determining the operational performance of such a donation system, proposing a food donation system as one of the solutions to food waste and loss. Because the supply of and demand for donated food is determined stochastically, simply increasing the amount of food donations would not necessarily be desirable in terms of beneficiaries or reduction of food waste and loss. In order to increase the amount of donated food, appropriate efforts should be made to collect the donated foods, and it may be more effective to increase the operating resources of food banks (e.g., employees, trucks) than simply increasing the number of farms that are willing to donate foods. They argued that matching the timing of donation between supply and demand is also important.

$\mathrm{Zu}$ Ermgassen et al. [19] reviewed policies and public and industrial barriers related to the use of wasted foods as animal feed in accordance with changes in EU legislation. It was pointed out 
that properly heat-treated food waste, as in the centralized food waste recycling system in Japan and Korea, can be used as safe and nutritious animal feeds. They suggested that the use of food scraps or residues can allow relatively cheap feed for pigs, while efforts are also needed to address consumer and agricultural producers' concerns about food safety and disease control. Pointing out that environmental benefits improve the profitability of many agricultural enterprises and help produce high-quality pork products, they emphasized that similar benefits could be discovered in other countries where the feed supply system using food waste is not currently common or is illegal.

Sonnino et al. [20] argued that the hospital's meal service generates food waste exceeding the publicly acceptable level in a case study of food waste and loss in hospitals in Wales, the United Kingdom. This study found that the overestimation on the demand for foods for the hospital meal service (especially hot foods) and excessive restriction on eating outside the pre-set meal hours were causing a lot of food waste and loss. It raised the need for a more integrated food waste reduction approach that linked all parties in the food chain. In addition, this study also emphasized the importance of an approach that integrated the hospital-level approach and the higher-level approach. It was suggested that policy and systematic guidelines such as educating employees, including procurement officers and facility managers, on the provision of meal services and improving communication between patients and hospital staffs were necessary.

Moult et al. [21] measured greenhouse gas emissions both by disposal method of food waste and by food item. Not only the emissions generated during transportation but also the emissions generated by food production were considered in this study. The disposal methods of food waste considered were food donation to food banks, conversion to animal feed, composting, and simple reclamation of food waste, among which the latest was remarked as the most inappropriate food waste disposal method. This study is differentiated from the existing research in that it compared and analyzed appropriate disposal methods from the perspective of the efficient reduction of greenhouse gas emissions, one of the ultimate goals of reducing food waste, and in that they emphasized the importance of food donation activities through food banks.

Caswell [22] suggested that the amount of food waste generated each year should be reduced to ensure a sustainable food system (food system) in the United Kingdom, and that there is a need for integrated effort and cooperation in various different stages of the food supply chain. In order for the food system as a whole to be better managed, Caswell [22] argued that the government and industry must cooperate in new attempts to reduce food waste and packaging waste, and actively help reduce the amount of food waste discharged from consumers. In particular, the need for education on specific food storage methods or on food waste and loss issues such as the financial benefits and value of environmental protection was emphasized. On the other hand, Fanelli and Nocera [23] highlighted the importance of national cooperation, including multi-stakeholder collaboration and private-public partnership in Europe.

To systematically reduce food waste, it is quite important to exactly measure the amount of food waste. Bellemare et al. [24] studied the measurement of the amount and value of food waste. Researchers' definitions of food waste range from the food system to the end of food waste landfill. They argued that, in terms of this definition, the amount of food waste was exaggerated. Specifically, an analysis of the value of food waste confirmed that existing estimates of most food waste values were exaggerated when determining the value of food waste and loss using retail prices instead of the prices observed in the upstream of the food supply chain. These findings suggest that resource or soil used to reduce food waste may have been used inefficiently. Bellemare et al. [24] estimated the amount of food waste and loss based on the difference between the supply of the U.S. food system and the food consumption by Americans. They found that food waste and loss had been gradually increasing, and they also claimed that this was due to the increased food availability and marketing in the food supply system, where food was cheap and easily available. Meanwhile, it was pointed out that solving food over-supply in the U.S. will not only reduce food waste that causes serious environmental problems but will also help curb obesity. Finally, Bellemare et al. [24] found that per capita food waste and loss 
in the United States have increased by about 50 percent since 1974, reaching more than $1400 \mathrm{kcal}$ a day per person or 150 trillion kcal a year. On the other hand, giordano et al. [25] examined three different measurements on the same sample of Italian households using data from one-week diary study. They found that the amount of household food waste significantly varies by the measurement methodology, suggesting the necessity both of a series of future studies on larger samples and of fixing the estimation of household food waste based on a valid method.

Fanelli and Romagnoli [26] investigated the impact of macroeconomic variables on annual per capita food waste using data from World Bank and the FAO. They found that the determinants of per capita food waste vary by country depending on demographic characteristic as well as on culture and tradition. Their findings provide insights that the efforts to reduce food waste may need to be regionally specific as the causes of food waste could have a geographical variation even within a country.

\subsection{Related Policies by International Organizations and Countries}

\subsubsection{Efforts of International Organizations}

Efforts to reduce food waste are underway worldwide. Not only are they carried out at the individual country level, but also at the international organization level; joint efforts by the coalition of countries are also being actively carried out.

In September 2015, the UN announced "Sustainable Development goal 12" as a key task to achieve sustainable consumption goals [27]. In particular, Sustainable Development goal 12.3 aims to measure the global Food Loss Index with the aim of halving per capita global food waste at retail and consumer levels by 2030 and to reduce food loss in the production and supply chain, including the post-harvest stage. Sustainable Development goal 12.5 aims to measure recycling rate and the weight of recycled foods within a country as a single indicator, and consequently to significantly reduce the amount of food waste by 2030 through prevention, reduction, recycling, and reuse.

Meanwhile, the FAO's global Initiative is also noteworthy as one of the efforts of the international community. In May 2011, the FAO and Trade Fair organizer Messe Düsselorf gmbH held the "Save Food" international conference at Interpack2011 in Düsseldorf, the world's largest trade show for the packaging industry [28]. Since this event, the FAO and Messee Düsselorf have initiated the global Initiative on Food Waste and Loss Reduction, which follows the four major principles: "(1) first, awareness raising on the impact of, and solutions for food loss and waste; (2) second, collaboration and coordination of world-wide initiatives on food loss and waste reduction; (3) third, policy, strategy and program development for food loss and waste reduction; and (4) fourth, support to investment programs and projects, implemented by private and public sectors." The global Action announced that it will co-work with various public and private partners in Europe as well as the EU project "Food Use for Social Innovation by Optimizing Waste Prevention Strategies (FUSIONS)" to address food waste in all sectors of the food supply chain.

In 2011, the United Nations Environment Program (UNEP) and the FAO jointly launched the Sustainable Food Systems Program (SFSP) to enhance the efficiency of resource use and to reduce the pollution intensity of food systems from production to consumption while addressing food and nutrition security issues. The program formed an extensive coalition of relevant stakeholders, including the government, food and fish producers, agricultural workers, retailers, and consumers. In Rio+20, 2012, the FAO also published a policy report on the future we wanted, "End Hunger and Transition to a Sustainable Agricultural and Food System" [28].

It is also worth referring to efforts to strengthen public-private partnerships to reduce food loss in the supply chain in the Asia-Pacific Economic Cooperation (APEC) region. Aiming to address post-harvest food loss and waste issues from the food supply chain by strengthening cooperation between the public and private sectors, APEC's multi-year project, "strengthening public-private partnerships to reduce food loss in the supply chain" was launched at the second APEC Food Security Ministers' Meeting in Kazakhstan in 2012. As part of the first phase of the project, a workshop was 
held in Taiwan in 2013, and the participants identified the major issues and challenges regarding post-harvest food loss, established preliminary methodologies, and reviewed the strategies and action plans for APEC member countries. In addition, expert consultations and seminars were also held to "strengthen public-private partnerships to reduce food loss in the supply chain". Subjects (or items) of the seminars included fruits and vegetables in 2014, fisheries and livestock in 2015, and waste and loss of foods at the consumer level in 2016. Based on the results of the workshop and seminars, the project has been revising the draft methodology of the APEC Food Waste and Loss Assessment [29].

On the other hand, it is also worth referring an international meeting of food policy experts from around the world conducted by OECD's Food Chain Analysis Network (FCAN). Starting with the first meeting in December 2010, the FCAN annual meeting was held twice to discuss food waste and loss issues [30]. The fourth round of meetings in June 2013 discussed "food waste and loss in the supply chain" and the eighth round in June 2016 targeted food waste and loss reduction in the retail and processing sector." In particular, experts on food waste discussed how to measure food waste and loss at the eighth meeting of the OECD in 2016 [31]. The FAO and International Food Policy Research Institute (IFPRI) representatives introduced efforts to cooperate with the private sector, the government, and civil society in the FAO-IFPRI technology platform on food loss and waste measurement and reduction. In addition, it was strongly recommended to update the existing OECD analysis on all strategies and programs in the private and public sectors regarding food waste and loss and to strengthen the voices of developing countries and agricultural producers in food waste and loss discussions (see Table 1).

Table 1. Efforts of International Organizations.

\begin{tabular}{|c|c|c|}
\hline Organization & Project & Content \\
\hline $\begin{array}{l}\text { United Nations } \\
\text { (UN) }\end{array}$ & $\begin{array}{l}\text { Sustainable Development goal } \\
12.3 \text { and } 12.5\end{array}$ & $\begin{array}{l}\text { - Measure global food loss index with the } \\
\text { aim of halving global food waste at retail } \\
\text { and consumer levels by } 2030 \\
\text { Reduce food loss in production and } \\
\text { post-harvest stages } \\
\text { Measure recycling rate and weight of } \\
\text { recycled foods within a country as a } \\
\text { single indicator }\end{array}$ \\
\hline $\begin{array}{l}\text { Food and Agriculture } \\
\text { Organization } \\
\text { (FAO) }\end{array}$ & $\begin{array}{l}\text { global Initiative on Food } \\
\text { Waste and Loss Reduction }\end{array}$ & $\begin{array}{l}\text { - Awareness raising of the impact of and } \\
\text { solutions for food loss and waste } \\
\text { Collaboration and coordination of } \\
\text { world-wide initiatives on food loss and } \\
\text { waste reduction } \\
\text { Policy, strategy, and program development } \\
\text { for food loss and waste reduction } \\
\text { Support to investment programs and } \\
\text { projects implemented by private and } \\
\text { public sectors }\end{array}$ \\
\hline $\begin{array}{l}\text { UN Environment Programme } \\
\text { (UNEP) and FAO }\end{array}$ & $\begin{array}{l}\text { Sustainable Food Systems } \\
\text { Program }\end{array}$ & $\begin{array}{l}\text { - } \quad \text { Enhance the efficiency of resource use } \\
\text { - Reduce the pollution intensity of food } \\
\text { systems from production to consumption } \\
\text { - } \quad \text { Address food and nutrition security issues }\end{array}$ \\
\hline
\end{tabular}


Table 1. Cont.

\begin{tabular}{|c|c|c|}
\hline Organization & Project & Content \\
\hline $\begin{array}{l}\text { Asia-Pacific Economic } \\
\text { Cooperation } \\
\text { (APEC) }\end{array}$ & $\begin{array}{l}\text { Strengthening Public-Private } \\
\text { Partnerships to Reduce Food } \\
\text { Loss in the Supply Chain }\end{array}$ & $\begin{array}{l}\text { - Strengthen public-private partnerships to } \\
\text { reduce food loss in the supply chain in the } \\
\text { Asia-Pacific Economic Cooperation region } \\
\text { - Address post-harvest food loss and } \\
\text { waste issues }\end{array}$ \\
\hline $\begin{array}{c}\text { Organization for Economic } \\
\text { Co-operation and Development } \\
\text { (OECD) }\end{array}$ & Food Chain Analysis Network & $\begin{array}{l}\text { Experts on food waste discussed how to } \\
\text { measure food waste and loss }\end{array}$ \\
\hline $\begin{array}{l}\text { OECD and International Food } \\
\text { Policy Research Institute } \\
\text { (IFPRI) }\end{array}$ & $\mathrm{n} / \mathrm{a}$ & $\begin{array}{l}\text { - Make efforts to cooperate with the private } \\
\text { sector, the government, and civil society } \\
\text { in the FAO-IFPRI technology platform } \\
\text { on food loss and waste measurement } \\
\text { and reduction }\end{array}$ \\
\hline
\end{tabular}

Source: [27-31].

\subsubsection{Policies by Country}

Individual countries are also making significant efforts towards reducing food waste and loss. It is necessary to refer to the Food Date Labeling Act in the United States, among several examples. In the U.S., there are no federal government standards for date labels except for infant formula, and in the absence of such a federal law, states follow a complex and diverse set of date-display methods. For this reason, the majority of consumers have difficulty identifying the date that the label means and are even throwing away edible foods. Additionally, several states prohibit or restrict the sale of expired food products, generating additional food waste. In May 2016, Senators Richard Blumenthal and Chellie Pingree proposed a bill in the Senate and the House to standardize the labeling of food dates across the United States. The Food Date Indication Act required the establishment of a dual-label system with two information labelling labels; one "quality date indication" and another "safety date indication". Under the Act, manufacturers may mark dates indicating the quality of food additives. However, the quality reference date is optional because quality may be subjective as long as the standard phrase is "best for use". A safety reference date is required for items that may be less safety-secure after the quality reference date under the statute. These food labels confirm the U.S. efforts to reduce food waste [32].

The EU's FUSIONS is being promoted as a more resource-efficient European project because it significantly reduces food waste. The project had operated for four years from August 2012 to July 2016 with the support of the "European Commission Framework Program 7". The project contributed to building a European multilateral stakeholder base that shared a vision and strategy to prevent food loss and waste across the entire supply chain through social innovation. In addition, through its key objectives, FUSIONS supported the delivery of a roadmap for resource-efficient Europe, the European Commission's goal of 50 percent reduction in food waste, and a goal of reducing the amount of resources in the food chain by 20 percent by 2020 [33,34].

In 2000, the UK Waste and Resource Execution Program (WRAP) was established to promote sustainable food waste management. The WARP is not only a charity (No 1159512) but also a guarantee agency (No 4125764) registered in Britain. WRAP's research helps prioritize measures to address significant carbon, water, and food waste in the UK's food and beverage supply chain. The Courtauld Commitment 2025 aims to reduce food and beverage-related waste and greenhouse gas emissions by more than one-fifth per person within a decade in the UK. Achieving this goal is expected to help Britain achieve the U.N. Sustainable Development goals of 12.3 by 2030 [35-37]. 
France has implemented a National Pact against Food Waste aimed at halving food waste by 2025. The aim is to introduce special provisions concerning supply to strengthen the prevention of food waste in the restaurant, catering, and canteen sectors. The Act on Food Donations is in effect, including the enforcement of the Ministerial Decree on 21 December 2009, which sets the temperature and hygiene requirements for foods donated by restaurants. Most warm foods (cooked at temperatures above $63^{\circ} \mathrm{C}$ ) cannot be serviced again and are not allowed to be reheated for donation. France has launched a digital campaign featuring posters with messages such as "Manger c'est bien, jeter aa crint! (Eating is great, throwing away is terrible!)" to raise awareness of food waste and on how to interpret expiration dates. In France, supermarkets have also led a campaign to reduce food waste on fruits and vegetables in order to increase consumer consumption of ugly fruits and vegetables [34].

\section{Data and Methods}

\subsection{Data and Summary Statistics}

The purpose of this study is to figure out the current status of Korean households regarding their food waste. In addition, this study was promoted to identify factors that influence the food waste of Korean households. At the beginning of the study, there were no representative statistics in Korea that looked into household food waste behaviors and perceptions on food waste. However, since the 2018 Consumer Behavior Survey for Foods conducted by the Korea Rural Economic Institute decided to add new questions about household food waste behavior and awareness, it is possible to understand the relationship between food consumption of households and food waste behaviors [8]. Respondents of the survey were asked about food waste behaviors as well as their demographic characteristics and food consumption behaviors. More specifically, daily food waste, change in the amount of food waste compared to the previous year, volume-rate food waste disposal systems, the main sources of household food waste, the level of efforts to reduce food waste, and perceptions on the importance of reducing food waste are newly included in the 2018 survey.

In 2018, the CBSF conducted a face-to-face sample survey of 3437 units representing Korean households during May through August in 2018. The CBSF has been nationally funded since 2013. Samples for the 2018 CBSF were extracted based on the stratification extraction method using as the sample extraction frame the 2010 Enumeration District and the list of 17,893,307 households provided by Statistics Korea.

The main meal planners in charge of purchasing foods in households responded to the 'questionnaire for main meal planner', while an average of two household members responded to the 'questionnaire for household members.' As this survey is about 'behaviors', most of the questions are asked in a Likert scale form. This study found that $87.78 \%$ of respondents to the survey were women and $12.22 \%$ were men, a natural phenomenon in Korea that occurred when people in charge of purchasing foods in households responded. Single-person and two-person households accounted for $22.35 \%$ and $39.66 \%$ of the total, respectively, with $21.12 \%$ for three-person households, $15.04 \%$ for four-person households, and $1.83 \%$ for five or more. The average age of respondents in the survey was 51.6 years old (11.88 years of standard deviation), with $29.36 \%$ of those in their 50 s accounting for the highest proportion. Among the participants in the survey, the minimum age was identified as 19, while the maximum age was 75 (see Table 2). 
Table 2. Sociodemographic characteristics of survey participants.

\begin{tabular}{|c|c|c|c|}
\hline \multicolumn{2}{|c|}{ Classification } & Percentage (\%) & Number of Participants (\#) \\
\hline \multirow{17}{*}{ Survey Area } & Seoul Metro City & 11.93 & 410 \\
\hline & Busan Metro City & 7.62 & 262 \\
\hline & Incheon Metro City & 5.79 & 199 \\
\hline & Daegu Metro City & 5.5 & 189 \\
\hline & Daejeon Metro City & 4.86 & 167 \\
\hline & gwangju Metro City & 4.48 & 154 \\
\hline & Ulsan Metro City & 3.52 & 121 \\
\hline & gyounggi Province & 12.28 & 422 \\
\hline & gyeongsangbuk-do & 6.95 & 239 \\
\hline & gyeongsangnam-do & 7.33 & 252 \\
\hline & Jeollabuk-do & 4.34 & 149 \\
\hline & Jeollanam-do & 5.56 & 191 \\
\hline & Chungcheongbuk-do & 5.76 & 198 \\
\hline & Chungcheongnam-do & 5.82 & 200 \\
\hline & gangwon-do & 6.43 & 221 \\
\hline & Jeju Island & 1.83 & 63 \\
\hline & Total & 100 & 3437 \\
\hline \multirow{3}{*}{ Gender } & Female & 87.78 & 3017 \\
\hline & Male & 12.22 & 420 \\
\hline & Total & 100 & 3437 \\
\hline \multirow{6}{*}{ Age } & 30 s or below & 17.66 & 607 \\
\hline & $40 \mathrm{~s}$ & 25.08 & 862 \\
\hline & $50 \mathrm{~s}$ & 29.36 & 1009 \\
\hline & $60 \mathrm{~s}$ & 20.45 & 703 \\
\hline & $70 \mathrm{~s}$ & 7.45 & 256 \\
\hline & Total & 100 & 3437 \\
\hline \multirow{6}{*}{$\begin{array}{l}\text { \# of people in a } \\
\text { household }\end{array}$} & 1 person & 22.35 & 768 \\
\hline & 2 people & 39.66 & 1363 \\
\hline & 3 people & 21.12 & 726 \\
\hline & 4 people & 15.04 & 517 \\
\hline & 5 people or more & 1.83 & 63 \\
\hline & Total & 100 & 3437 \\
\hline
\end{tabular}

Note: The first author of this paper was in charge of the 2018 Consumer Behavior Survey for Foods (CBSF) in the Korea Rural Economic Institute, and the corresponding author was in charge of in-depth analysis using the survey data. Source: The data were obtained from [8].

\subsection{Econometric Analysis}

\subsubsection{Analysis of Factors Affecting the Amount of Food Waste}

In the 2018 CBSF, respondents were asked to select a specific range (less than $500 \mathrm{~g}$, more than $500 \mathrm{~g}$ and less than $1 \mathrm{~kg}$, more than $1 \mathrm{~kg}$ and less than $2 \mathrm{~kg}$, more than $2 \mathrm{~kg}$ end less than $3 \mathrm{~kg}$, and more than $3 \mathrm{~kg}$ ) of the amount of food waste discharged from their households. Because these responses were categorical, an ordered logit model was adopted in the analysis of factors affecting the amount of food waste discharged from households. If the amount of food waste, $y_{i}^{*}$, is within a certain range, the 
respondent chooses $j$ among $J$ alternatives. Therefore, the relationship between unobservable $y_{i}^{*}$ and observable $y_{i}$ is shown in Equation (1). In Equation (1), $X, \beta$, and $\varepsilon$ are vector or explanatory variables, vector of coefficients, and error term, respectively.

$$
\begin{array}{cc}
y_{i}^{*}=X \beta+\varepsilon_{i}, & i=1,2, \ldots, I \\
y_{i}=1, & y_{i}^{*} \leq \mu_{1} \\
y_{i}=2, & \mu_{1}<y_{i}^{*} \leq \mu_{2} \\
& \ldots \\
y_{i}=J-1, & \mu_{J-2}<y_{i}^{*} \leq \mu_{J-1} \\
y_{i}=J, & \mu_{J-1}<y_{i}^{*}
\end{array}
$$

In Equation (1), values from $\mu_{1}$ to $\mu_{J-1}$ become the criterion for selecting $j$ out of a total number of $J$ observable responses as they are the boundary value of $y^{*}$. If the cumulative distribution function, $F(\cdot)$, is changed to the cumulative logit distribution function in the same way as the classical binary logit model and its inverse function is taken, as shown in Equation (1), then the ordered logit model can finally be obtained, which is found in Equation (2). In Equation (2), $F(\cdot)$ and $\operatorname{Pr}(\cdot)$ represent the cumulative distribution function and probability of occurrence of an event, respectively.

$$
\begin{gathered}
\operatorname{Pr}\left(y_{i}=1\right)=\operatorname{Pr}\left(y_{i}^{*} \leq \mu_{1}\right)=\operatorname{Pr}\left(\varepsilon_{i} \leq \mu_{1}-X \beta\right)=F\left(\mu_{1}-X \beta\right)=\frac{e^{\mu_{1}-X \beta}}{1+e^{\mu_{1}-X \beta}} \\
\operatorname{Pr}\left(y_{i}=J-1\right)=\operatorname{Pr}\left(\mu_{J-2}<y_{i}^{*} \leq \mu_{J-1}\right)=\operatorname{Pr}\left(\mu_{J-2}-X \beta<\varepsilon_{i} \leq \mu_{J-1}-X \beta\right) \\
=F\left(\mu_{J-1}-X \beta\right)-F\left(\mu_{J-2}-X \beta\right)=\frac{e^{\mu_{J-1}}-X \beta}{1+e_{J-1}-X \beta}-\frac{e^{\mu_{J-2}-X \beta}}{1+e^{\mu_{J}-2^{-X \beta}}} \\
\operatorname{Pr}\left(y_{i}=J\right)=\operatorname{Pr}\left(\mu_{J-1}<y_{i}^{*}\right)=\operatorname{Pr}\left(\mu_{J-1}-X \beta<\varepsilon_{i}\right)=1-F\left(\mu_{J-1}-X \beta\right) \\
=1-\frac{e^{\mu_{J}-1^{-}-X \beta}}{1+e^{\mu_{J}-1^{-X \beta}}}
\end{gathered}
$$

The logarithm of Equation (2) is shown in Equation (3).

$$
\ln \left[\frac{\operatorname{Pr}\left(y_{i} \leq j\right)}{\operatorname{Pr}\left(y_{i}>j\right)}\right]=\left[\frac{F\left(\mu_{j}-X \beta\right)}{1-F\left(\mu_{j}-X \beta\right)}\right]=\mu_{j}-X \beta, \quad j=1,2, \ldots, J-1
$$

In our analysis of factors affecting the amount of food waste discharged from households, the model has been set up by assuming that the amount of food waste discharged by consumers $\left(y_{i}\right)$ would depend on the patterns of purchasing foods and food waste disposal methods as well as demographic factors such as age, gender, and educational background (Equation (4)). All the variables in Equation (4) will be discussed and defined in the latter section.

$$
Y_{i}=\beta_{0}+\beta_{1} \text { DemographicFactor }_{i}+\beta_{2} \text { BuyingPattern }_{i}+\beta_{3} \text { DisposalMethod }_{i}+\beta_{3}+\varepsilon_{i}
$$

3.2.2. Analysis of Differences in the Amount of Food Waste by Intensity of Efforts and by Household Awareness on Reducing Food Waste

The respondents who participated in the survey were classified into two groups based on the intensity of food waste reduction efforts. Based on this classification, this study investigated the differences in factors affecting the amount of food waste discharged from households in Korea. For the question asking the level of efforts that have been made to reduce food waste, the participants who answered 'not trying at all', 'not trying', and 'average' were classified into group 1, while those who responded 'trying' and 'trying very hard' were classified into group 2.

Second, the households who participated in the 2018 CBSF were classified into two groups based on the level of the awareness of importance of food waste reduction. Again, this study examined the differences in the impact of the awareness of importance of food waste reduction between the two groups. Participants who answered that food waste reduction was 'not important at all', 'not 
important', and 'average' were classified into group 1, and those who evaluated 'important' and 'very important' were classified into group 2.

\section{Empirical Results and Discussions}

\subsection{Descriptive Statistics}

\subsubsection{Food Waste Discharge in Korea}

This study found that most Korean households discharge less than $1 \mathrm{~kg}$ of food waste a day. Approximately $63 \%$ of households discharge food waste of less than $500 \mathrm{~g}$ a day, while about $31 \%$ discharge food waste of more than $500 \mathrm{~g}$ but less than $1 \mathrm{~kg}$ a day (see Table 2).

Amount of food waste discharged was the highest in all upper-level administrative districts at 'less than $500 \mathrm{~g}^{\prime}$, with approximately $79 \%$ and $47 \%$ of participants, respectively, in gyeongsangbuk-do and Daegu Metro City discharging less than $500 \mathrm{~g}$. This suggests that regional differences in food waste discharge could exist significantly (see Table 2). This regional difference may stem from the facts that the level of efforts to reduce food waste vary by local government, and that agricultural products and foods that are mainly produced and eaten also vary by local government. Therefore, the policies related to reducing food waste need to be designed and carried out by reflecting the regional characteristics.

This study also found that, as the number of household members increases, the amount of food waste generally increases. This is an expected difference because the higher the number of household members, the higher the amount of food left over from cooking and consequently the higher the amount of food waste generated after eating (Table 3). This finding is also consistent with previous studies $[14,26]$ in which a similar pattern was found.

Table 3. Amount of Food Waste Discharged by Household Type.

\begin{tabular}{|c|c|c|c|c|c|c|c|}
\hline \multicolumn{2}{|c|}{ Classification } & \multirow{2}{*}{$\begin{array}{c}\begin{array}{c}\text { Below } 500 \mathrm{~g} \\
(\%)\end{array} \\
64.39\end{array}$} & \multirow{2}{*}{$\begin{array}{c}500 \mathrm{~g}-1 \mathrm{~kg}(\%) \\
28.78 \\
\end{array}$} & \multirow{2}{*}{$\begin{array}{c}\text { 1-2 kg (\%) } \\
4.88\end{array}$} & \multirow{2}{*}{$\begin{array}{c}\mathbf{2 - 3} \text { kg (\%) } \\
1.95\end{array}$} & \multirow{2}{*}{$\begin{array}{c}\begin{array}{c}\text { Above } 3 \mathbf{~ k g} \\
(\%)\end{array} \\
0.00\end{array}$} & \multirow{2}{*}{$\begin{array}{c}\begin{array}{c}\text { Number of } \\
\text { Participants } \\
\text { (\#) }\end{array} \\
410\end{array}$} \\
\hline \multirow{12}{*}{$\begin{array}{l}\text { Upper-level } \\
\text { Administrative } \\
\text { District }\end{array}$} & Seoul Metro City & & & & & & \\
\hline & Busan Metro City & 52.67 & 43.89 & 2.67 & 0.76 & 0.00 & 262 \\
\hline & Incheon Metro City & 66.83 & 27.14 & 6.03 & 0.00 & 0.00 & 199 \\
\hline & Daegu Metro City & 46.56 & 34.39 & 13.23 & 3.17 & 2.65 & 189 \\
\hline & gwangju Metro City & 58.44 & 39.61 & 1.30 & 0.65 & 0.00 & 154 \\
\hline & Ulsan Metro City & 50.41 & 42.15 & 6.61 & 0.83 & 0.00 & 121 \\
\hline & gyounggi Province & 58.53 & 29.86 & 9.95 & 1.66 & 0.00 & 422 \\
\hline & gyeongsangbuk-do & 78.66 & 19.67 & 1.67 & 0.00 & 0.00 & 239 \\
\hline & Chungcheongbuk-do & 65.66 & 33.33 & 1.01 & 0.00 & 0.00 & 198 \\
\hline & Chungcheongnam-do & 76.00 & 23.50 & 0.50 & 0.00 & 0.00 & 200 \\
\hline & gangwon-do & 62.44 & 34.39 & 3.17 & 0.00 & 0.00 & 221 \\
\hline & Jeju Island & 69.84 & 25.40 & 4.76 & 0.00 & 0.00 & 63 \\
\hline \multirow{2}{*}{ Gender } & Female & 61.88 & 32.28 & 4.67 & 0.99 & 0.17 & 3017 \\
\hline & Male & 72.14 & 25.00 & 2.38 & 0.48 & 0.00 & 420 \\
\hline \multirow{3}{*}{$\begin{array}{c}\text { Age of household } \\
\text { head }\end{array}$} & 30 s or below & 66.89 & 28.34 & 4.28 & 0.33 & 0.16 & 607 \\
\hline & $40 \mathrm{~s}$ & 51.97 & 39.33 & 7.31 & 1.16 & 0.23 & 862 \\
\hline & $50 \mathrm{~s}$ & 59.07 & 35.38 & 4.36 & 1.09 & 0.10 & 1009 \\
\hline
\end{tabular}


Table 3. Cont.

\begin{tabular}{|c|c|c|c|c|c|c|c|}
\hline \multicolumn{2}{|c|}{ Classification } & \multirow{2}{*}{$\begin{array}{c}\begin{array}{c}\text { Below } 500 \mathrm{~g} \\
(\%)\end{array} \\
86.59\end{array}$} & \multirow{2}{*}{$\begin{array}{c}\mathbf{5 0 0} \mathrm{g}-\mathbf{1} \mathbf{~ k g ~ ( \% )} \\
11.85\end{array}$} & \multirow{2}{*}{$\begin{array}{c}\mathbf{1 - 2} \mathrm{kg}(\%) \\
1.04\end{array}$} & \multirow{2}{*}{$\begin{array}{c}2-3 \mathrm{~kg}(\%) \\
0.52\end{array}$} & \multirow{2}{*}{$\begin{array}{c}\begin{array}{c}\text { Above } 3 \mathbf{~ k g} \\
(\%)\end{array} \\
0.00\end{array}$} & \multirow{2}{*}{$\begin{array}{c}\begin{array}{c}\text { Number of } \\
\text { Participants } \\
\text { (\#) }\end{array} \\
768\end{array}$} \\
\hline \multirow{3}{*}{ Household size } & 1 person & & & & & & \\
\hline & 3 persons & 51.38 & 41.18 & 6.20 & 1.24 & 0.00 & 726 \\
\hline & 4 persons & 44.68 & 44.10 & 9.48 & 1.16 & 0.58 & 517 \\
\hline \multicolumn{2}{|c|}{ Total } & 63.14 & 31.39 & 4.39 & 0.93 & 0.15 & 3437 \\
\hline
\end{tabular}

Compared to the previous year, $0.32 \%$ of households responded that the amount of food waste has decreased significantly, $7.86 \%$ answered that the amount has somewhat decreased, while about $13 \%$ of survey participants responded that the amount has increased (Table 4 ). This finding means that food waste is on the rise over time in Korea (even though it is just a simple comparison with 2017). Despite efforts to reduce food waste in Korea as well as around the world, the fact that food waste in Korea increased compared to the previous year indirectly suggests that more active encouragement and intervention with regard to food waste issues by policymakers are needed in Korea.

Table 4. Increase or decrease in the amount of food waste discharged compared to last year.

\begin{tabular}{cccc}
\hline \multicolumn{2}{c}{ Classification } & Percentage (\%) & Number of Participants (\#) \\
\hline \multirow{3}{*}{ Change in amount of food waste } & decreased significantly & 0.32 & 11 \\
\cline { 2 - 4 } & somewhat decreased & 7.86 & 270 \\
\cline { 2 - 4 } & not changed & 79.28 & 2725 \\
\cline { 2 - 4 } & somewhat increased & 12.45 & 428 \\
\cline { 2 - 4 } & increased significantly & 0.09 & 3 \\
\cline { 2 - 4 } & Total & 100 & 3437 \\
\hline
\end{tabular}

Source: The data were obtained from [8].

\subsubsection{Volume-Rate Food Waste Disposal System}

It turned out that the most widely used volume-rate food waste disposal system in Korea was public food waste collection boxes $(29.44 \%)$, as can be seen in apartments or multi-household residence. The second was the exclusive containers only for food waste $(28.78 \%)$, and food waste bags are also widely used (25.02\%), followed by the Radio-Frequency Identification (RFID) method (11.14\%) (see Table 5). Although public food waste collection boxes still account for the highest proportion in Korea, both exclusive containers and RFID methods are rapidly spreading. When taking into account the fact that the amount of food waste discharged may vary by volume-rate food waste disposal system, more in-depth analyses on the relationship between the disposal system and the amount of food waste need to be conducted in further studies.

\subsubsection{Main Source of Food Waste}

The main source of food waste is also of interest as it is the main cause of the problem we face with regard to food waste. This study found that the largest portion of food waste in Korea is generated in the pre-cooking stage (for example, fruit peel and vegetable or fish dressing), accounting for $54.52 \%$ of the total. The second largest portion of food waste is generated in the after-meal stage (for example, rice, side dishes, or soup leftovers), accounting for $40.38 \%$ of the total (see Table 6 ). Therefore, to reduce household food waste in Korea, policymakers may focus on the pre-cooking stage, probably by activating fresh-cut vegetable markets. Fanelli [14] found that the main causes of food waste was 'expired food (1.06/5.00)' followed by 'bad smell (0.80/5.00)', 'bad taste $(0.79 / 5.00)$ ', and 'mold 
(0.63/5.00).' It seems that our finding is consistent with Fanelli [14] as 'expired food', 'bad smell', 'bad taste', and 'mold' are the causes of the pre-cooking stage.

Table 5. Volume-rate food waste disposal system.

\begin{tabular}{ccc}
\hline Classification & Percentage (\%) & Number of Participants (\#) \\
\hline Radio-Frequency Identification (RFID) method & 11.14 & 383 \\
\hline Exclusive containers only for food waste & 28.78 & 989 \\
\hline Bag for food waste & 25.02 & 860 \\
\hline $\begin{array}{c}\text { Public food waste collection boxes (as in } \\
\text { apartments or multi-household residence) }\end{array}$ & 29.44 & 1012 \\
\hline Others & 5.62 & 193 \\
\hline Total & 100 & 3437 \\
\hline
\end{tabular}

Table 6. Main sources of household food waste in Korea.

\begin{tabular}{ccc}
\hline Classification & Percentage (\%) & Number of Participants (\#) \\
\hline Leftover rice, side dishes, or soup scraps & 40.38 & 1388 \\
\hline $\begin{array}{c}\text { Pre-cooking stage } \\
\text { (fruit peel and vegetable or fish dressing) }\end{array}$ & 54.52 & 1874 \\
\hline Spoiled or old foods & 5.09 & 175 \\
\hline Total & 100 & 3437 \\
\hline
\end{tabular}

Source: The data were obtained from [8].

\subsubsection{Household Efforts to Reduce Food Waste and Their Recognition on Food Waste}

Regarding household efforts to reduce food waste in Korea, approximately $51 \%$ of the survey participants responded that they were trying to reduce food waste, while about $45 \%$ of participants answered 'average' (see Table 7). This finding indicates that there are still many households in Korea that are not making an active effort to reduce food waste. Overall, the proportion of households that are making an active effort (tend to try and trying very hard) is generally higher for women, households with more members, and those in their 40s and 50s. The level of efforts to reduce food waste in Korea varies by region. Specifically, the score indicating the level of efforts was lowest in the Daekyung area of Korea (3.29/5.00) and highest for the Seoul Metropolitan area (3.61/5.00).

Table 7. Efforts to reduce food waste by household type.

\begin{tabular}{|c|c|c|c|c|c|c|c|}
\hline Classificatio & & $\begin{array}{l}\text { No Effort } \\
\text { at All (\%) }\end{array}$ & $\begin{array}{l}\text { Tend Not } \\
\text { to Try (\%) }\end{array}$ & $\begin{array}{c}\text { Average } \\
(\%)\end{array}$ & $\begin{array}{l}\text { Tend to } \\
\text { Try (\%) }\end{array}$ & $\begin{array}{c}\text { Trying Very } \\
\text { Hard (\%) }\end{array}$ & $\begin{array}{c}\text { Number of } \\
\text { Participants (\#) }\end{array}$ \\
\hline \multirow{2}{*}{ Gender } & Female & 0.1 & 3.4 & 43.5 & 50.5 & 2.5 & 3017 \\
\hline & Male & 0.5 & 3.8 & 57.6 & 36.4 & 1.7 & 420 \\
\hline \multirow{5}{*}{ Age of household head } & $\begin{array}{l}\text { 30s or } \\
\text { below }\end{array}$ & 0.3 & 2.1 & 49.3 & 46.3 & 2.0 & 607 \\
\hline & $40 \mathrm{~s}$ & 0.00 & 3.6 & 41.8 & 53.0 & 1.6 & 862 \\
\hline & $50 \mathrm{~s}$ & 0.00 & 3.0 & 42.4 & 52.2 & 2.4 & 1009 \\
\hline & $60 \mathrm{~s}$ & 0.1 & 4.4 & 47.9 & 45.0 & 2.6 & 703 \\
\hline & $70 \mathrm{~s}$ & 1.2 & 4.7 & 51.2 & 37.1 & 5.9 & 256 \\
\hline
\end{tabular}


Table 7. Cont.

\begin{tabular}{|c|c|c|c|c|c|c|c|}
\hline \multicolumn{2}{|c|}{ Classification } & $\begin{array}{l}\text { No Effort } \\
\text { at All (\%) }\end{array}$ & $\begin{array}{l}\text { Tend Not } \\
\text { to Try (\%) }\end{array}$ & $\begin{array}{c}\text { Average } \\
(\%)\end{array}$ & $\begin{array}{l}\text { Tend to } \\
\text { Try (\%) }\end{array}$ & $\begin{array}{c}\text { Trying Very } \\
\text { Hard (\%) }\end{array}$ & $\begin{array}{c}\text { Number of } \\
\text { Participants (\#) }\end{array}$ \\
\hline \multirow{5}{*}{$\begin{array}{l}\text { Household } \\
\text { size }\end{array}$} & 1 person & 0.4 & 4.8 & 55.5 & 36.6 & 2.7 & 768 \\
\hline & 2 persons & 0.2 & 3.7 & 46.6 & 46.7 & 2.7 & 1363 \\
\hline & 3 persons & 0.0 & 2.2 & 37.6 & 58.7 & 1.5 & 726 \\
\hline & 4 persons & 0.0 & 2.1 & 38.1 & 57.6 & 2.1 & 517 \\
\hline & $\begin{array}{l}5 \text { persons } \\
\text { or more }\end{array}$ & 0.0 & 3.2 & 38.1 & 54.0 & 4.8 & 63 \\
\hline \multirow{6}{*}{ Region } & $\begin{array}{c}\text { Seoul } \\
\text { Metropolitan }\end{array}$ & 0.0 & 2.8 & 36.2 & 58.2 & 2.7 & 1031 \\
\hline & Chungcheong & 0.0 & 0.6 & 49.0 & 45.0 & 5.4 & 565 \\
\hline & Honam & 0.0 & 4.9 & 45.0 & 47.7 & 2.4 & 557 \\
\hline & Daekyung & 1.7 & 6.9 & 53.0 & 37.7 & 0.7 & 428 \\
\hline & Dongnam & 0.0 & 2.6 & 52.7 & 43.8 & 0.9 & 635 \\
\hline & Kangwon & 0.0 & 5.9 & 56.8 & 32.4 & 4.9 & 221 \\
\hline \multicolumn{2}{|c|}{ Total } & 0.2 & 3.4 & 45.2 & 48.8 & 2.4 & 3437 \\
\hline
\end{tabular}

It was also found that recognition on the importance of food waste reduction is overall very high in Korea. About 63\% of participants responded that food waste reduction is 'somewhat important' or 'really important' (see Table 8). The proportion of participants recognizing the importance of food waste reduction is generally higher for women and households with more members.

Table 8. Recognition on the importance of reducing food waste by household type.

\begin{tabular}{|c|c|c|c|c|c|c|c|}
\hline \multicolumn{2}{|c|}{ Classification } & \multirow{2}{*}{$\begin{array}{c}\begin{array}{c}\text { Not } \\
\text { Important at } \\
\text { All (\%) }\end{array} \\
0.0\end{array}$} & \multirow{2}{*}{$\begin{array}{c}\begin{array}{c}\text { Not Really } \\
\text { Important } \\
(\%)\end{array} \\
0.9\end{array}$} & \multirow{2}{*}{$\begin{array}{c}\begin{array}{c}\text { Average } \\
(\mathbf{\%})\end{array} \\
34.7\end{array}$} & \multirow{2}{*}{$\begin{array}{c}\begin{array}{c}\text { Somewhat } \\
\text { Important (\%) }\end{array} \\
58.5\end{array}$} & \multirow{2}{*}{$\begin{array}{c}\begin{array}{c}\text { Really } \\
\text { Important } \\
(\%)\end{array} \\
5.9 \\
\end{array}$} & \multirow{2}{*}{$\begin{array}{c}\begin{array}{c}\text { Number of } \\
\text { Participants } \\
\text { (\#) }\end{array} \\
3017\end{array}$} \\
\hline Conder & Female & & & & & & \\
\hline Gertus & Male & 0.0 & 0.7 & 45.0 & 49.8 & 4.5 & 420 \\
\hline \multirow{4}{*}{ Age of household head } & $\begin{array}{l}30 \text { s or } \\
\text { below }\end{array}$ & 0.0 & 0.7 & 37.7 & 56.2 & 5.4 & 607 \\
\hline & $50 \mathrm{~s}$ & 0.0 & 1.0 & 33.2 & 59.6 & 6.2 & 1009 \\
\hline & $60 \mathrm{~s}$ & 0.0 & 1.1 & 37.2 & 56.2 & 5.4 & 703 \\
\hline & $70 \mathrm{~s}$ & 0.0 & 1.2 & 43.0 & 50.4 & 5.5 & 256 \\
\hline \multirow{2}{*}{ Household size } & 1 person & 0.0 & 0.9 & 46.0 & 47.7 & 5.5 & 768 \\
\hline & $\begin{array}{l}5 \text { persons } \\
\text { or more }\end{array}$ & 0.0 & 0.0 & 28.6 & 66.7 & 4.8 & 63 \\
\hline \multicolumn{2}{|l|}{ Total } & 0.0 & 0.8 & 35.9 & 57.4 & 5.8 & 3437 \\
\hline
\end{tabular}

\subsection{Estimation Results}

Table 9 shows the estimation results of Equation (4) based on an ordered logit model. From the econometric analysis of the relationship between demographic factors and the amount of food waste discharge, this study found that the older the household head, the higher the number of people in the household, and the higher the level of final education of the household head, the higher the probability of food waste being discharged from the household. The probability of discharging more food waste is higher for single-person households than for two or more person households, which is a reasonable finding because the frequency and amount of meals cooked is lower for single-person households. 
It was concluded that gender does not affect the amount of food waste at the $10 \%$ signification level, and the amount of food waste discharged from rural (Eup/Myeon) area households was not significantly different from the amount of food waste discharged from urban households.

Table 9. Estimation of factors affecting amount of food waste.

\begin{tabular}{|c|c|c|c|}
\hline \multicolumn{2}{|c|}{ Classification } & Coefficient Estimate & Standard Error \\
\hline \multirow{9}{*}{ Demographic factors } & Age & $0.0084^{* *}$ & 0.0043 \\
\hline & Number of household members & $0.2983^{* * *}$ & 0.0472 \\
\hline & Highest level of education & $0.2762 * * *$ & 0.0663 \\
\hline & gender $($ male $=1)$ & -0.0956 & 0.1256 \\
\hline & Single-person household & $-0.9895^{* * *}$ & 0.1419 \\
\hline & Eup/Myeon area (rural) & -0.1195 & 0.1020 \\
\hline & Housing: House-type & -0.0811 & 0.1201 \\
\hline & Housing: Apartment & 0.0014 & 0.1173 \\
\hline & Housing: Others & $1.7957^{* * *}$ & 0.4665 \\
\hline \multirow[t]{2}{*}{ Pattern of purchasing foods } & $\begin{array}{l}\text { Average amount of groceries } \\
\text { purchased at a time }\end{array}$ & $0.0045^{* * *}$ & 0.0011 \\
\hline & grocery shopping cycle & -0.0857 & 0.0542 \\
\hline \multirow{4}{*}{ Volume-rate disposal system } & Exclusive container & 0.0373 & 0.1401 \\
\hline & Volume-rate bag & $-0.5201 * * *$ & 0.1384 \\
\hline & Public food waste collection box & $-0.3463 * * *$ & 0.1263 \\
\hline & Others & $-0.6148^{* *}$ & 0.2441 \\
\hline \multirow{7}{*}{ Estimation results } & /cut1 & \multicolumn{2}{|c|}{2.1455} \\
\hline & /cut2 & \multicolumn{2}{|c|}{4.6247} \\
\hline & /cut3 & \multicolumn{2}{|c|}{6.3187} \\
\hline & /cut4 & \multicolumn{2}{|c|}{8.3363} \\
\hline & \# of sample & \multicolumn{2}{|c|}{3437} \\
\hline & $\operatorname{LR}\left(\chi^{2}(15)\right.$ & \multicolumn{2}{|c|}{$457.7^{* * *}$} \\
\hline & Pseudo $\mathrm{R}^{2}$ & \multicolumn{2}{|c|}{0.0789} \\
\hline
\end{tabular}

Note: ${ }^{* *}$ and ${ }^{* *}$ denote $10 \%$ and $5 \%$ significance level, respectively. Source: The data were obtained from [8].

In addition to demographic factors, meanwhile, patterns of purchasing foods are important factors that influence the amount of food waste discharge. This study found that the greater the average expenditure on purchasing groceries at one time, the greater the probability of discharging more food waste. This is considered an acceptable result because households with a high average of one-time expenditure on foods use more raw materials and ingredients than those who do not, or because they store more in the fridge. On the other hand, it was analyzed that the grocery shopping cycle did not affect the amount of food waste at the $10 \%$ significance level. The shorter the grocery shopping cycle (i.e., the more frequently you purchase), the lower the food waste discharge. The fact that the grocery shopping cycle is not a statistically significant factor implies that how much food you purchase at a time rather than the grocery shopping cycle may have a more significant effect on food waste discharge for households.

This study also found no statistically significant difference in the amount of food waste between households using exclusive containers and those using RFID systems (base group). However, the amount of food waste was found to be smaller for households using either volume-rate bags (need to purchase food waste exclusive bags) or public food waste collection boxes of apartments or multi-unit dwellings (jointly pay for all the management expenses) than those using RFID systems. 
Table 10 represents the estimation results of the analysis of the effect of intensity of efforts to reduce food waste on the amount of food waste discharged from households using the same ordered logit model in Equation (4).

Table 10. Estimation of factors affecting amount of food waste by intensity of efforts to reduce food waste.

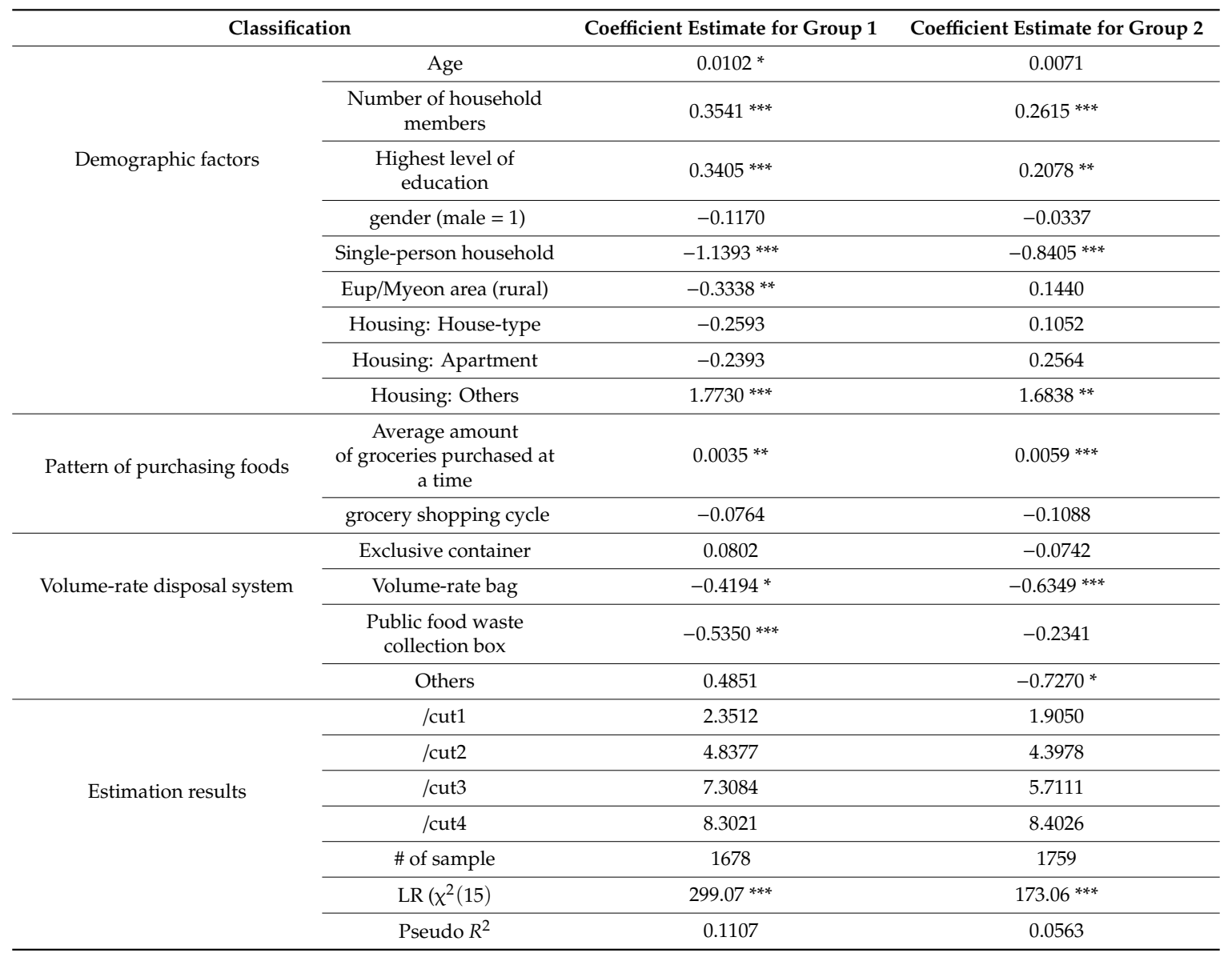

Note: ${ }^{*}, * * * *$ denote $10 \%, 5 \%$, and $1 \%$ significance level, respectively. Source: The data were obtained from [8].

This study found that age and residential area (Eup/Myeon; rural areas) have a significant relationship to the amount of food waste for group 1, which has made a higher level of efforts to reduce food waste. However, those factors are not statistically significant for group 2. For the group who is making a lower level of effort to reduce (Group 2), older or rural area residents are more likely to have more food waste discharged from households.

While, for both groups, the grocery shopping cycle was concluded to have no statistically significant impact on the amount of food waste discharged, it was estimated that the higher the amount of foods purchased at one time, the higher the probability of more food waste discharged from the households. In terms of the volume-rate disposal system, the volume-rate bag system had a statistically significantly lower amount of food waste than the RFID approach for both groups. Public food waste collection boxes are likely to involve less food waste compared to the RFID system for the group with the lower level of efforts to reduce food waste (Group 2).

Table 11 represents the estimation results of the analysis of the effect of awareness of importance of food waste reduction on the amount of food waste discharged from households using the same ordered logit model in Equation (4). 
Table 11. Estimation of factors affecting amount of food waste by level of awareness of importance to reduce food waste.

\begin{tabular}{|c|c|c|c|}
\hline \multicolumn{2}{|c|}{ Classification } & \multirow{2}{*}{$\begin{array}{c}\text { Coefficient Estimate for Group 1 } \\
0.0100\end{array}$} & \multirow{2}{*}{$\begin{array}{c}\text { Coefficient Estimate for Group 2 } \\
0.0069\end{array}$} \\
\hline \multirow{9}{*}{ Demographic factors } & Age & & \\
\hline & $\begin{array}{l}\text { Number of household } \\
\text { members }\end{array}$ & $0.2874^{* * *}$ & $0.2957^{* * *}$ \\
\hline & $\begin{array}{l}\text { Highest level of } \\
\text { education }\end{array}$ & $0.3971^{* * *}$ & $0.1913^{* *}$ \\
\hline & gender $($ male $=1)$ & $-0.3839 * *$ & 0.0689 \\
\hline & Single-person household & $-1.1307^{* * *}$ & $-0.9140 * * *$ \\
\hline & Eup/Myeon area (rural) & -0.2695 & -0.0351 \\
\hline & Housing: House-type & $-0.3487^{*}$ & 0.0594 \\
\hline & Housing: Apartment & -0.3198 & 0.1647 \\
\hline & Housing: Others & $1.3749^{* *}$ & $2.0393^{* * *}$ \\
\hline \multirow[t]{2}{*}{ Pattern of purchasing foods } & $\begin{array}{c}\text { Average amount } \\
\text { of groceries purchased at } \\
\text { a time }\end{array}$ & 0.0020 & $0.0061 * * *$ \\
\hline & grocery shopping cycle & -0.0425 & $-0.1166^{*}$ \\
\hline \multirow{4}{*}{ Volume-rate disposal system } & Exclusive container & 0.2013 & -0.0329 \\
\hline & Volume-rate bag & -0.1000 & $-0.6955^{* * *}$ \\
\hline & $\begin{array}{l}\text { Public food waste } \\
\text { collection box }\end{array}$ & -0.3422 & $-0.3076^{* *}$ \\
\hline & Others & -0.2736 & $-0.6460 *$ \\
\hline \multirow{7}{*}{ Estimation results } & /cut1 & 2.5743 & 1.8265 \\
\hline & /cut2 & 5.2097 & 4.2602 \\
\hline & /cut3 & 9.1761 & 5.6787 \\
\hline & /cut4 & - & 7.6770 \\
\hline & \# of sample & 1265 & 2172 \\
\hline & $\operatorname{LR}\left(\chi^{2}(15)\right.$ & $196.32^{* * *}$ & $265.18^{* * *}$ \\
\hline & Pseudo $R^{2}$ & 0.1041 & 0.0685 \\
\hline
\end{tabular}

Note: ${ }^{*}, * * * * *$ denote $10 \%, 5 \%$, and $1 \%$ significance level, respectively. Source: The data were obtained from [8].

This study found that the number of household members and educational background were significant factors for both groups. On the other hand, the impact of gender was statistically significant for group 1, whose awareness of the importance of food waste reduction is low, while it was not significant for group 2, whose level of awareness of the importance of reducing food waste is high. For group 2, which has a high level of awareness of the importance of food waste reduction, there is no statistical difference in the amount of food waste discharged by residential type, whereas there is a high probability that residents of other housing types are more likely to have more food waste discharged than other types of housing. For group 1, with a low awareness of the importance of food waste reduction, it was estimated that the purchase patterns were not all significant factors affecting food waste discharge, while for group 2, with a high level of awareness of the importance of food waste reduction, those two patterns of purchasing foods had a statistically significant impact on the amount of food waste discharge. For group 2, with a high level of awareness of the importance of reducing food waste, this study found that the higher the average amount of food purchased at a time, the higher the probability that more food waste was discharged from households. In addition, the less frequently foods are purchased, the more likely households are to have less food waste. For group 1 , with the low level of awareness of the importance of reducing food waste, the amount of food waste discharged statistically significantly varies by the volume-rate disposal system. For group 2 , with a high level of awareness of the importance of food waste reduction, the amount of food waste discharged was statistically significantly less for volume-rate bags, public food waste collection boxes, and other system than for the RFID system. 


\subsection{Discussions and Policy Implications}

\subsubsection{Efforts to Reduce Food Waste and Loss}

Efforts by international organizations and individual countries to reduce food waste and loss continue, and related researches are also being actively conducted. Among many international organizations' efforts to reduce food waste and loss, the UN is making consistent efforts to develop indicators that can measure food waste and loss through Sustainable Development goal 12, and to set goals for countries around the world to participate.

OECD is also making various efforts to derive policy priorities as well as to develop related indicators through an international meeting by a group of experts in the field of food policies, called the Food Chain Analysis Network (FCAN). OECD-FCAN meetings also aim to provide a venue for stakeholders and policy makers to work together.

Other efforts are being made by the FAO, UNEP, and APEC to establish a comprehensive system of cooperation between the private sectors and public sectors. Investigating the current state of national efforts to reduce food waste and loss, this study found that there are some differences in the content of efforts for each country. In the United States, a law called the Food Date Indication Act has been proposed, and efforts are underway to reduce food waste, mostly at the consumption stage, through the revision of the law. In the United Kingdom, various policies and cooperation are being pursued to set common goals and achieve them on a more comprehensive level, including water and resources as well as food waste. In the case of the EU, similar efforts are underway to strengthen the monitoring of food waste and loss and to establish relevant guidelines in line with the characteristics that many member countries in the region have. In the case of France, a specific and comprehensive approach is under way to reduce food waste and loss in the food supply stage including restaurants as well as in the consumption stage related to food labeling.

Researches on food waste and loss can be divided into three main categories: (1) the study on the information to be provided to consumers, food labeling, public-private partnerships, etc.; (2) the study on the methodology of reducing food waste and loss and on the methodology of recycling foods; and (3) the study of developing measurement methods and indicators for measuring food waste and loss.

\subsubsection{Implications of the Analysis of Factors Affecting Food Waste of Korean Households}

As a result of analyzing the factors affecting food waste discharges for Korean households, most of the factors considered in the analysis, such as demographic factors and purchasing patterns and volume-rate disposal system, were seen to affect the amount of food waste. These are in line with the results of Secondi et al. [12] and Radzymińska, et al. [10], which showed that consumer characteristics are significantly related to the individual's behavior toward food waste. The findings that the difference in the amount of food waste disposed by households depends on not only the purchase patterns but also the volume-rate disposal system provide policy implications. The analysis indicated that the households with large food expenditure at one time produce more food waste in Korea. This suggests that the implementation of campaigns and education that encourage people to only purchase as much food as they need could be an effective way to reduce household food waste. It was also concluded that the volume-rate disposal system, such as RFID, exclusive containers, and volume-rate bag methods, can also change the amount of food waste, which means that it is necessary to find and develop an optimal disposal system that can reduce food waste discharge. The optimal disposal system may vary by region and the socioeconomic status of people. As suggested by Fanelli and Nocera [23], the implementation of campaigns and education is also of interest for policymakers. For future researches for the case of Korea, the purpose, material, communication channels, relevant initiatives and governance, and ways of providing information of such awareness raising campaigns should be explored.

The matter of whether or not efforts were being made to reduce food waste was not generating a systematic, statistically significant difference in the amount of food waste in Korea. However, 
in the different levels of awareness of the importance of reducing food waste, each factor has a different effect on food waste discharge. This is consistent with the results of Refsgaard and Magnussen [11], which showed that behaviors toward food waste are influenced by knowledge on food waste reduction and recycling and knowledge of consequences of food waste. This implies that if policy efforts to raise awareness of the importance of reducing food waste are made, for example, the aforementioned campaigns for changing purchasing patterns, dietary education, and discovery of an effective volume-rate disposal system, then food waste reduction can be achieved more efficiently.

\subsubsection{Suggestions for Responding to Food Waste and Loss Issue}

In Korea, efforts to reduce food waste and loss have long been made at the level of the central government, local government, and private organizations. Various campaigns have been carried out to reduce food waste, and there are various methods to charge food waste through volume-rate systems. However, an accurate measurement of the size of food waste and loss has never been sought, and specific goals for food waste and loss reduction or policy implementation plans to achieve them were also never been set up.

In this situation, we would like to suggest four major measures to cope with food waste and loss (see Figure 1). First, it is necessary to actively participate in the international community's efforts to cope with food waste and loss. Currently, the international community is working to develop relevant indicators and establish action plans and initiatives in response to the challenge of food waste and loss. It is necessary to actively participate in international projects to induce the establishment of international standards that can be applied to Korea and to establish its status as a leading country that leads in reducing food waste and loss.

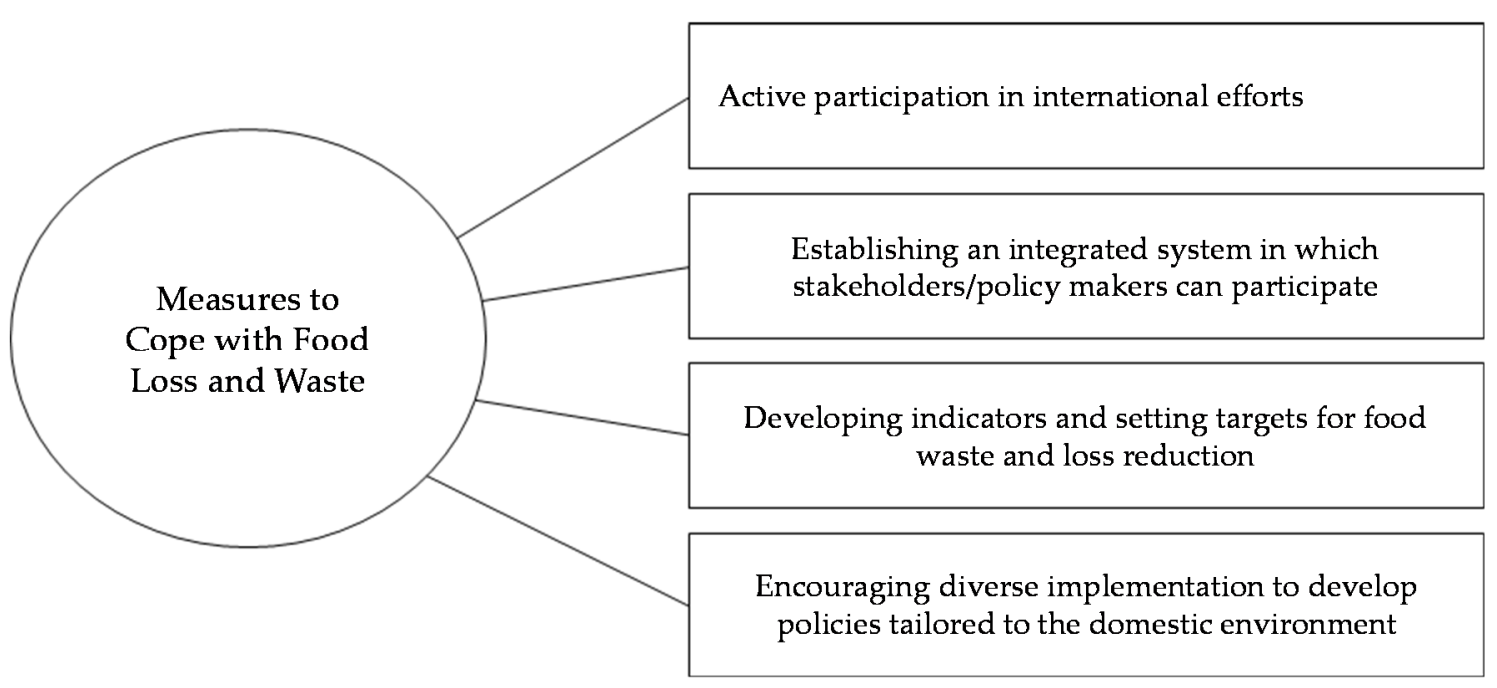

Figure 1. Measures to Cope with Food Loss and Waste.

Second, it would also be necessary to develop an integrated system that can monitor comprehensively the production to consumption stages and can reduce food waste and loss; such a system should ensure that all stakeholders can participate and cooperate with each other. For instance, stakeholders who are affected by the changes in the display of various 'dates' for foods and the prevention of over-serving of foods in restaurants need to be included in the interested parties. Changes in the plan will be possible when both suppliers and consumers have fully discussed the issues and come to an agreement. It should also be able to identify food waste and loss in the stages along the food supply chain and provide information to stakeholders and policymakers.

Third, it will be necessary to set targets for food waste and loss reduction based on social consensus. To do this, first of all, indicators must be developed to measure the size of food waste and 
loss. Implementation plans or guidelines that can be used in central and local governments, the public and private sectors, and the supply and demand sectors should be provided.

Finally, various studies should be carried out to reduce food waste and loss. In the case of food waste and loss, there are not many direct stakeholders; thus, related private-level research is not active. Because policy objectives have not been set, little policy research has been carried out. Because food waste and loss occur at various levels and in various forms, and depending on the characteristics of each country, the structure of the food supply chain, consumer characteristics, cultural characteristics, and related legislation, it is necessary to develop policies suitable for the domestic environment to suppress food waste and loss; for this, a lot of research must be carried out in Korea as well.

\section{Conclusions}

Tremendous efforts to reduce food waste have been made internationally and at the country level because food waste is closely associated with critical global issues such as hunger and sustainable development, climate change and environmental burden, economic losses, etc. However, there are only a few academic researches and policy movements in Korea. One of the many causes of this inactivity is the lack of relevant statistics on household food waste behaviors. This study is the first comprehensive study on the food waste behaviors of Korean households and its determinant that utilizes the new questions of a national household survey conducted annually since 2013 by the Korea Rural Economic Institute. Based on the analysis of this first representative national-level household survey, this study provides several useful insights and policy implications for countries with a similar environment and situation to Korea.

First, this study found that approximately $63 \%$ of households discharge food waste of less than $500 \mathrm{~g}$ a day, and the amount varies by region significantly, implying a potential possibility of food waste reduction by regionally differentiated strategies. Not only the amount of food waste but also other food waste behaviors vary by region; the policies related to reducing food waste need to be designed and carried out by fully reflecting the regional characteristics.

Second, the results indicated that the most widely used volume-rate disposal system in Korea is public food waste collection boxes $(29.44 \%)$, followed by exclusive containers manufactured for food waste $(28.78 \%)$ and trash bags $(25.02 \%)$. The fact that the difference in share among the top three disposal systems is not significant suggests that there exists a potential to reduce food waste by promoting changes to an effective disposal system in the future. When taking into account the fact that the amount of food waste discharged may vary by volume-rate food waste disposal systems, more in-depth analyses on the relationship between the disposal system and the amount of food waste need to be conducted in further studies.

Third, this analysis found that the main source of food waste in Korea is the pre-cooking stage (for example, fruit peel and vegetable or fish dressing), which accounts for $54.52 \%$ of the total. The second largest portion of food waste is generated in the after-meal stage (for example, rice, side dishes, or soup leftovers), accounting for $40.38 \%$ of the total. The efforts to reduce household food waste in each country must be based on such statistics. For example, a two-track approach might be needed in Korea for which the policy efforts to reduce food waste in the pre-cooking stage and in the after-meal stage must be made. The former efforts include the activation of the fresh-cut or frozen fruit and vegetable industry, while examples of latter efforts are an awareness raising campaign and education.

Fourth, the efforts and the awareness on the importance of reducing food waste vary by household type, implying that policy efforts to raise consumers' awareness must be tailored for each household type by reflecting such statistics. For example, the Korean government's efforts will have to find an appropriate method for households with male and younger heads, and for single-person households, as the awareness level is relatively lower for those households. Perhaps implementation of campaigns or education through SSN or YouTube channels, which they mainly use, might be more appropriate.

Fifth, regression analyses indicate that policy efforts should focus on raising awareness of the importance of reducing food waste, for example, by promoting campaigns to encourage desirable food 
purchases, implementing dietary education, and discovering an optimal volume-rate disposal system that is regionally specific.

Finally, this study suggest that central governments of countries similar to Korea should actively participate in international efforts, establish an integrated system in which stakeholders and policy makers can cooperate, develop indicators and set targets for food waste reduction, and encourage diverse implementation to develop policies tailored to domestic and regional environment.

The food waste issue has become an important one that human beings must cope with jointly and actively resolve. The governments of every country will have to formulate and implement plans to reduce food waste. It is believed that the household survey on food waste behaviors that began in 2018 in Korea to better understand the actual situation of food waste could be a starting point for this policy effort.

Author Contributions: Study design, S.K. and S.H.L.; data collection, S.K.; data analysis, S.K. and S.H.L.; original draft preparation, S.K. and S.H.L. All authors have read and agreed to the published version of the manuscript.

Funding: This work was funded by the Korea Rural Economic Institute (No. E21-2018).

Acknowledgments: This research is a modified version of the report entitled "Responding to OECD Research Network for Sustainable Agriculture and Rural Areas" that was published by the Korea Rural Economic Institute in 2018.

Conflicts of Interest: The authors declare no conflict of interest.

\section{References}

1. Food and Agriculture Organization of the United Nations. Food Wastage Footprint: Impacts on Natural Resources. Available online: http://www.fao.org/3/i3347e/i3347e.pdf (accessed on 20 June 2020).

2. Gustavsson, J.; Cederberg, C.; Sonesson, U.; Emanuelsson, A. The Methodology of the FAO Study: global Food Losses and Food Waste. Available online: http://www.diva-portal.org/smash/record.jsf?pid=diva2\% 3A944159\&dswid=-85 (accessed on 20 June 2020).

3. United Nations. Transforming Our World: The 2030 Agenda for Sustainable Development. Available online: https://www.unfpa.org/sites/default/files/resource-pdf/Resolution_A_RES_70_1_EN.pdf (accessed on 14 July 2020).

4. Food and Agriculture Organization of the United Nations. global food losses and food waste. Available online: http://www.fao.org/3/mb060e/mb060e00.htm (accessed on 20 June 2020).

5. The Ministry of Environment. A Study on the Plan to Introduce the Volume-Based Food Waste Rate System and Reduction Policy. 2010; Policy Report. Available online: http://www.prism.go.kr/homepage/ researchCommon/downloadResearchAttachFile.do;jsessionid=7C03D2E30D874DEF4F96F7A2A276AA4C. node02?work_key=001\&file_type=CPR\&seq_no=001\&pdf_conv_yn=N\&research_id=1480000-201100465 (accessed on 20 June 2020). (In Korean)

6. The Ministry of Environment. A Study on Food Waste Treatment Status and Management Plan. 2017; Policy Report. Available online: http://www.prism.go.kr/homepage/researchCommon/ downloadResearchAttachFile.do?work_key=001\&file_type=CPR\&seq_no=001\&pdf_conv_yn=N\& research_id=1480000-201600023 (accessed on 20 June 2020). (In Korean)

7. The Ministry of Environment. A Study on Improvement Plan of Food Waste Management Policy. 2015; Policy Report. Available online: http://www.prism.go.kr/homepage/researchCommon/ downloadResearchAttachFile.do;jsessionid=A0122B149DE1762646EE19EC1D102AEB.node02?work_ key $=002 \& f i l e \_t y p e=C P R \& s e q \_n o=001 \& p d f \_c o n v \_y n=Y \& r e s e a r c h \_i d=1480000-201500011$ (accessed on 20 June 2020). (In Korean)

8. Korea Rural Economic Institute. Consumer Behavior Survey for Foods for 2018. Available online: http: //www.krei.re.kr/foodSurvey/selectBbsNttList.do?bbsNo=451\&key=809 (accessed on 7 August 2020).

9. Qi, D.; Roe, B.E. Household Food Waste: Multivariate Regression and Principal Components Analyses of Awareness and Attitudes among U.S. Consumers. PLoS ONE 2016, 11, e0159250. [CrossRef] [PubMed]

10. Radzymińska, M.; Jakubowska, D.; Staniewska, K. Consumer Attitude and Behaviour towards Food Waste. J. Agribus. Rural. Dev. 2016, 10, 175-181. [CrossRef] 
11. Refsgaard, K.; Magnussen, K. Household behaviour and attitudes with respect to recycling food waste-Experiences from focus groups. J. Environ. Manag. 2009, 90, 760-771. [CrossRef] [PubMed]

12. Secondi, L.; Principato, L.; Laureti, T. Household food waste behaviour in EU-27 countries: A multilevel analysis. Food Policy 2015, 56, 25-40. [CrossRef]

13. Halloran, A.; Clement, J.; Kornum, N.; Bucatariu, C.; Magid, J. Addressing food waste reduction in Denmark. Food Policy 2014, 49, 294-301. [CrossRef]

14. Fanelli, R.M. Using Causal Maps to Analyse the Major Root Causes of Household Food Waste: Results of a Survey among People from Central and Southern Italy. Sustainability 2019, 11, 1183. [CrossRef]

15. Falasconi, L.; Cicatiello, C.; Franco, S.; Segrè, A.; Setti, M.; Vittuari, M. Such a Shame! A Study on Self-Perception of Household Food Waste. Sustainability 2019, 11, 270. [CrossRef]

16. Qi, D.; Roe, B.E. Foodservice Composting Crowds Out Consumer Food Waste Reduction Behavior in a Dining Experiment. Am. J. Agric. Econ. 2017, 99, 1159-1171. [CrossRef]

17. Miller, B.D.D.; Welch, R.M. Food system strategies for preventing micronutrient malnutrition. Food Policy 2013, 42, 115-128. [CrossRef]

18. Lee, D.; Sönmez, E.; gómez, M.I.; Fan, X. Combining two wrongs to make two rights: Mitigating food insecurity and food waste through gleaning operations. Food Policy 2017, 68, 40-52. [CrossRef]

19. Zu Ermgassen, E.K.; Phalan, B.; green, R.E.; Balmford, A. Reducing the land use of EU pork production: Where there's swill, there's a way. Food Policy 2016, 58, 35-48. [CrossRef] [PubMed]

20. Sonnino, R.; McWilliam, S. Food waste, catering practices and public procurement: A case study of hospital food systems in Wales. Food Policy 2011, 36, 823-829. [CrossRef]

21. Moult, J.; Allan, S.; Hewitt, C.; Berners-Lee, M. greenhouse gas emissions of food waste disposal options for UK retailers. Food Policy 2018, 77, 50-58. [CrossRef]

22. Caswell, H. Britain's battle against food waste. Nutr. Bull. 2008, 33, 331-335. [CrossRef]

23. Fanelli, R.M.; Di Nocera, A. How to implement new educational campaigns against food waste: An analysis of best practices in European Countries. Econ. Agro-Aliment. Food Econ. 2017, 19, 223-244. [CrossRef]

24. Bellemare, M.F.; Çakir, M.; Peterson, H.H.; Novak, L.; Rudi, J. On the Measurement of Food Waste. Am. J. Agric. Econ. 2017, 99, 1148-1158. [CrossRef]

25. Giordano, C.; Piras, S.; Boschini, M.; Falasconi, L. Are questionnaires a reliable method to measure food waste? A pilot study on Italian households. Br. Food J. 2018, 120, 2885-2897. [CrossRef]

26. Fanelli, R.M.; Romagnoli, L. Annual food waste per capita as influenced by geographical variations. Riv. DI Studi Sulla Sostenibilità 2019, 1, 59-76. [CrossRef]

27. Sustainable Consumption and Production. Available online: https:/www.un.org/sustainabledevelopment/ sustainable-consumption-production/ (accessed on 22 October 2018).

28. Food and Agriculture Organization of the United Nations. Reduction of Food Losses and Waste in Europe and Central Asia for Improved Food Security and Agrifood Chain Efficiency. Available online: http://www.fao.org/3/a-au844e.pdf (accessed on 11 August 2020).

29. APEC Strengthening Public-Private Partnership to Reduce Food Losses in the Supply Chain. Available online: http://www.mofa.go.kr/eng/brd/m_5465/down.do?brd_id=8116\&seq=315089\&data_tp=A\&file_seq=1 (accessed on 22 October 2018).

30. Food Chain Analysis Network. Available online: https://www.oecd.org/agriculture/topics/food-chainanalysis-network/ (accessed on 22 October 2018).

31. OECD. The Summary Report. In Proceedings of the 8th Meeting of the OECD Food Chain Analysis Network on Reducing Food Loss and Waste in Retail and Processing Sectors, Paris, France, 23-24 June 2016.

32. Food Date Labeling Act. Available online: https:/www.refed.com/tools/food-waste-policy-finder/federalpolicy/food-date-labeling-act (accessed on 22 October 2018).

33. About Fusions. Available online: http://www.eu-fusions.org/index.php/about-fusions\#: \{\}:text=FUSIONS\% 20(Food\%20Use\%20for\%20Social,European\%20Commission\%20Framework\%20Programme\%207 (accessed on 22 October 2018).

34. France-Summary of Policies and Legislation for Food Waste Prevention and Reduction. Available online: https://www.eu-fusions.org/index.php/country-reports/reports/292-france (accessed on 22 October 2018).

35. Food Waste Reduction. Available online: http://www.wrap.org.uk/food-waste-reduction (accessed on 22 October 2018). 
36. Our History. Available online: http://www.wrap.org.uk/about-us/our-history (accessed on 22 October 2018).

37. Resource Revolution: Creating the Future. Available online: http://www.wrap.org.uk/about-us/our-plan\#: $\sim\{\}:$ text=Our $\% 20$ five $\% 20$ year $\% 20$ plan $\% 2 C \% 20 \backslash$ T1 $\backslash$ textquoterightResource,define $\% 20$ how $\% 20$ we $\% 20$ use $\%$ 20materials (accessed on 22 October 2018).

Publisher's Note: MDPI stays neutral with regard to jurisdictional claims in published maps and institutional affiliations.

(C) 2020 by the authors. Licensee MDPI, Basel, Switzerland. This article is an open access article distributed under the terms and conditions of the Creative Commons Attribution (CC BY) license (http://creativecommons.org/licenses/by/4.0/). 